\title{
Genome-wide identification and expression analysis of PUB genes in cotton
}

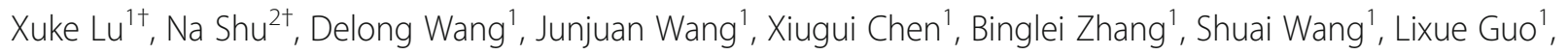
Chao Chen ${ }^{1}$ and Wuwei Ye $\mathrm{i}^{1^{*}}$

\begin{abstract}
Background: The U-box gene encodes a ubiquitin ligase that contain U-box domain. The plant U-box gene (PUB) plays an important role in the response to stresses, but few reports about PUBs in cotton were available. Therefore research on PUBs is of great importance and a necessity when studying the mechanisms of stress- tolerance in cotton.

Results: In this study, we identified 93, 96, 185 and 208 PUBs from four sequenced cotton species G. raimondii $\left(D_{5}\right), G$. arboreum $\left(A_{2}\right), G$. hirsutum $\left(A D_{1}\right)$ and $G$. barbadense (AD2), respectively. Prediction analysis of subcellular localization showed that the PUBs in cotton were widely localized in cells, but primarily in the nucleus. The PUBs in cotton were classified into six subfamilies (A-F) on the basis of phylogenetic analysis, which was testified by the analysis of conserved motifs and exon-intron structures. Chromosomal localization analysis showed that cotton PUBs were unevenly anchored on all chromosomes, varying from 1 to 14 per chromosome. Through multiple sequence alignment analysis, 3 tandem duplications and 28 segmental duplications in cotton genome $D_{5}, 2$ tandem duplications and 25 segmental duplications in $A_{2}$, and 143 homologous gene pairs in $A_{2}$ and $D_{5}$ were found; however no tandem duplications in $A_{2}$ or $D_{5}$ were found. Additionally, 105, 14 and 17 homologous gene pairs were found in the intrasubgenome of At and Dt, At sub-genome and Dt sub-genome of G. hirsutum, respectively. Functional analysis of GhPUB85A and GhPUB45D showed that these genes positively responded to abiotic stresses, but the expression patterns were different. In addition, although the expression levels of these two homologous genes were similar, their contributions were different when responding to stresses, specifically showing different responses to abiotic stresses and functional differences between the two subgenomes of $G$. hirsutum.
\end{abstract}

Conclusions: This study reported the genome-wide identification, structure, evolution and expression analysis of PUBs in cotton, and the results showed that the PUBs were highly conserved throughout the evolutionary history of cotton. All PUB genes were involved in the response to abiotic stresses (including salt, drought, hot and cold) to varying degrees.

Keywords: U-box domain, PUB gene, Cotton, Evolution, Collinearity, Homologous gene pairs

\section{Background}

The ubiquitin-mediated ubiquitination pathway is the post-translational modification pathway of eukaryotic proteins. Studies have demonstrated that the pathway is

\footnotetext{
* Correspondence: yew158@163.com

${ }^{+}$Xuke Lu and Na Shu contributed equally to this work.

${ }^{1}$ State Key Laboratory of Cotton Biology/ Institute of Cotton Research,

Chinese Academy of Agricultural Sciences / Key Laboratory for Cotton Genetic Improvement, Anyang 455000, Henan, China

Full list of author information is available at the end of the article
}

involved in the cell cycles of higher plants [1], stress resistance [2], signal transduction [3], apoptosis [4], optical signal [5] and other physiological pathways. In the ubiquitin pathway, three steps are required for ubiquitin to act on the target protein. First, the ubiquitin-activating enzyme (E1) activates ubiquitin [1], and then the activated $\mathrm{Ub}$ molecules are delivered to the ubiquitinbinding enzyme (E2) [2]; finally, the Ub molecules are transferred to the target protein through ubiquitin ligase (E3) to work. In the pathway, E3 is critical for the

(c) The Author(s). 2020 Open Access This article is licensed under a Creative Commons Attribution 4.0 International License, which permits use, sharing, adaptation, distribution and reproduction in any medium or format, as long as you give appropriate credit to the original author(s) and the source, provide a link to the Creative Commons licence, and indicate if changes were made. The images or other third party material in this article are included in the article's Creative Commons licence, unless indicated otherwise in a credit line to the material. If material is not included in the article's Creative Commons licence and your intended use is not permitted by statutory regulation or exceeds the permitted use, you will need to obtain permission directly from the copyright holder. To view a copy of this licence, visit http://creativecommons.org/licenses/by/4.0/ The Creative Commons Public Domain Dedication waiver (http://creativecommons.org/publicdomain/zero/1.0/) applies to the data made available in this article, unless otherwise stated in a credit line to the data. 
identification of the specific substrate protein and can be found in the most species [3]. In Arabidopsis, there are more than 1400 genes encoding functional components of the ubiquitination pathway, of which approximately $90 \%$ genes were related to ubiquitin ligase E3 [3, 4]. Based on the composition of subunits and functional mechanism, the ubiquitin ligase E3 can be categorized into single-subunit type, such as HECT, RING/U-box [5] and multi-subunit type, such as SCF (skp1-cullin-F-box), APC (anaphase-promoting complex) [6], VBC (VHL-Elongin B-Elongin C) [7, 8], etc.

PUBs have been reported in many model crops, including Arabidopsis, rice, Chlamydomonas reinhardtii, Chinese cabbage, and soybean. Previous studies reported 64 PUBs were identified in Arabidopsis [9], 77 in rice [10], 33 in Chlamydomonas reinhardtii [11], 101 in Chinese cabbage [12] and 125 in soybean [13], indicating that PUB genes are widely distributed in plants. Many studies have shown that PUB proteins are involved in abiotic stress responses. Cho et al. obtained U-box E3 protein (CaPUB1) from water-stressed hot pepper plants and found CaPUB1-overexpressing plants displayed increased sensitivity water stress and mild salinity [14]. In Arabidopsis, proteins AtPUB22 and AtPUB23 were all negatively involved in the drought response by synergistic ubiquitination of RPN12a [15]. Liu et al. identified a U-box E3 protein AtPUB19 which was ep-regulated by drought, salt, cold and ABA. Down-regulation of AtPUB19 led to hypersensitivity to ABA, enhancing ABA-induced stomatal closing, and drought tolerance, while overexpression of AtPUB19 resulted in the reverse phenotypes [16]. Previous studies also showed that the drought resistance of OSPUB15-overexpressing plants was significantly enhanced, and OsPUB15 could be induced by hydrogen peroxide, drought and salt, indicating that OsPUB15 positively regulated the drought response by attenuating intracellular oxidative stress [17].

Cotton is the most important fiber crop and the model crop for research into polyploidy, evolution, cell wall development, and cellulose synthesis [18]. Approximately 50 cotton species were distributed in arid and semi- arid regions of the tropic and subtropics, which were presumed to have originated from the same ancestor 50 to 100 million years ago [19]. The current cultivars are diploid G. arboreum and G. herbaceum, and tetraploid G. hirsutum and G. barbadense. The tetraploid cottons originated from the hybridization of an African ancestral species with A genome and an American ancestor species with D genome one to two million years ago [18]. Recently the sequencing work of diploid cottons G. raimondii (D5) [20, 21] and G. arboreum (A2) [22], and allotetraploid cottons G. hirsutumtm-1 (AD1) [23, 24] and G. barbadense acc.3-79 (AD2) [25] were completed, providing references for the study of gene function and evolution at the whole genome level. Based on the cotton genome sequences, the research about the genome-wide identification, structure, evolutionary relationship and expression analysis of PUBs would be well conducted, and this could provide some evaluable information for the functional analysis of PUBs in in cotton in the future.

\section{Results \\ Genome-wide identification of PUB gene family members in cotton}

The hidden Markov model (HMM) of the U-box domain (PF04564) was downloaded from the Pfam30.0 database, and used as a query to identify the candidate PUB members in four cotton genomic database using HMMER3.0. SMART. In addition, Pfam 30.0 was also used for further identification to confirm every PUB members containing U-box domain. Finally, 93, 96, 185, and 208 PUBs were identified from the four sequenced cotton species G. raimondii $\left(\mathrm{D}_{5}\right)$, G. arboreum $\left(\mathrm{A}_{2}\right), \mathrm{G}$. hirsutum acc. TM-1 ( $\left.\mathrm{AD}_{1}\right)$, and G. barbadense (AD2), respectively, and these PUBs were named GrPUB1-93, GaPUB1-96, GhPUB1A-89A/1D-91D/181-185 and GbPUB1A-98A/1D-98D/197-208 according to their location on the chromosome. The number of PUB genes in tetraploid cottons was twice as high as that in diploid cottons, showing that PUB genes were relatively conservative. The essential information about the gene name, chromosome locations, length of the open reading frame (ORF), type of protein domain, position of the U-box domain and subcellular localizations of these gene family members could be found in additional files (Additional file 2: Table S2, Additional file 3: Table S3, Additional file 4: Table S4 and Additional file 5: Table S5). The length of the PUB protein sequence in the cotton ranged from 49 to $1492 \mathrm{AA}$, and the U-box domain contained approximately 75 amino acids. However, the length of the U-box domain was almost identical except for a few PUBs; for example, proteins GaPUB39 and GhPUB40D had only 32 and 50 amino acids, respectively. Results of the subcellular localization analysis showed PUB proteins could be found throughout the cell, including nuclear, cytoplasmic, chloroplast, plasma membrane, mitochondrial, and extracellular locations. However, most PUB proteins were localized inside the nucleus. Twenty different domains were found among all the cotton PUBs (Table 1), and the primary mode was " $\mathrm{U}$ box+ARM/HEAT". Different domain modes may be associated with different functions of cotton PUBs.

\section{Structure and evolution analysis of PUBs in cotton}

A Gene structure diagram of the PUBs and an evolution tree were constructed (Additional file 6: Fig. S1, Additional file 7: Fig. S2, Additional file 8: Fig. S3 and Additional file 9: Fig. S4). Based on the evolutionary relationship, the PUB genes could be categorized into 
Table 1 Domain organizations of PUB proteins in cotton

\begin{tabular}{|c|c|c|c|c|c|}
\hline \multirow[t]{2}{*}{ No. } & \multirow{2}{*}{$\begin{array}{l}\text { Composition of domain } \\
\text { (from } \mathrm{N} \text { end to } \mathrm{C} \text { end) }\end{array}$} & \multicolumn{4}{|c|}{ Number of proteins } \\
\hline & & G.raimondii & G.arboreum & G. hirsutum & G. barbadense \\
\hline 1 & UFD2 specific motif + U-box & 1 & 1 & 2 & 2 \\
\hline 2 & U-box + ARM & 43 & 45 & 78 & 90 \\
\hline 3 & U-box only & 33 & 35 & 68 & 83 \\
\hline 4 & STYKc + U-box & 3 & 3 & 6 & 7 \\
\hline 5 & S_TKc + U-box & 3 & 3 & 6 & 6 \\
\hline 6 & U-box + Prp19+WD40 & 3 & 2 & 3 & 6 \\
\hline 7 & U-box + WD40 & 2 & 2 & 6 & 3 \\
\hline 8 & $\mathrm{TPR}+\mathrm{U}-\mathrm{box}$ & 1 & 2 & 3 & 3 \\
\hline 9 & U-box + PPlase & 1 & 1 & 2 & 2 \\
\hline 10 & $U-b o x+K A P$ & 1 & 0 & 1 & 0 \\
\hline 11 & UspA + S_TKc + U-box & 2 & 2 & 2 & 2 \\
\hline 12 & UspA + STYKc + U-box & 0 & 0 & 2 & 1 \\
\hline 13 & NRAMP + U-box + ARM & 0 & 0 & 2 & 0 \\
\hline 14 & $A n k+U-b o x+A R M$ & 0 & 0 & 1 & 0 \\
\hline 15 & Ank + U-box + ARM + Ank & 0 & 0 & 1 & 0 \\
\hline 16 & RPOL_N + RNA_pol + U-box + ARM & 0 & 0 & 1 & 0 \\
\hline 17 & U-box + WD40 + S_TKc & 0 & 0 & 1 & 0 \\
\hline 18 & $E G F+P A N \_A P+U-b o x+A R M$ & 0 & 0 & 0 & 1 \\
\hline 19 & U-box + Arm + DNA_pol3 & 0 & 0 & 0 & 1 \\
\hline 20 & Pkinase + U-box & 0 & 0 & 0 & 1 \\
\hline
\end{tabular}

five subgroups (I-V). Among these subgroups, subgroup I was composed of the domains "U-box + ARM" and "U-box only", and the remaining subgroups were composed of the other domains. The exon number of PUB genes in cotton was greatly divergent, ranging from 1 to 25. Among all the PUBs, approximately $1 / 3$ of the PUBs contained only one exon. Generally, the evolutionary relationship is correlated with gene structure in some way, that is, exons with the more similarities in terms of the number and size of the exon, have a closer evolutionary relationship. In G. hirsutum, the length of GhPUB1A is $47 \mathrm{~Kb}$, much larger than the other PUB genes, which may be correlated with the assembly and annotation of the cotton genome. Members in each subgroup of $G$. barbadense (AD2) was much different with those in G. raimondii $\left(\mathrm{D}_{5}\right)$, G. arboreum $\left(\mathrm{A}_{2}\right)$ and G. hirsutum $\left(\mathrm{AD}_{1}\right)$, and this difference may be correlated with the different origins of these species. Therefore, the PUBs in G. raimondii $\left(\mathrm{D}_{5}\right), \mathrm{G}$. arboreum $\left(\mathrm{A}_{2}\right)$ and $\mathrm{G}$. hirsutum $\left(\mathrm{AD}_{1}\right)$ were used for the evolution relationship analysis, and the results also indicated five subgroups namedi-vwere found (Additional file 10: Fig. S5), and this was similar with the evolution of PUBs in one genome, indicating the PUB members were highly conservative. Furthermore, closer evolution relationships of GhPUB1A-89A with GaPUB1-96 and GhPUB1D-91D with GaPUB1-93 were found through the evolutionary analysis.
Chromosomal localization analysis of PUB genes in three cotton genomes

The MapInspect software was used to analyze the localization of PUB genes on the chromosomes based on the position information. Among 93 genes in G. raimondii, 91 were localized unevenly on the chromosome and the others were found on scaffolds (Fig. 1a). These results indicated that only a few genes were present on chromosomes 3,4 , and 12 , and the chromosome 5 contained the highest number of PUB genes (11 PUBs). In addition, PUB genes on chromosomes 4, 6, 7, 11 and 12 were preferentially enriched towards the end of the chromosome. All of 96 PUB genes identified in G. arboreum were localized on different chromosomes (Fig. 1b). The results showed uneven distribution of PUBs on each chromosome in G. arboretum, chromosome 1 containing the most PUB genes (up to 14) and chromosome 3 containing the least PUB genes (only 2). In addition, the length of chromosome 5 was approximately $6 \mathrm{Mb}$, however 9 PUB genes were found on it, presenting the highest distribution density. In G. hirsutum, 91.4\% (169/185) of the PUB genes were anchored onto chromosomes, as shown in Fig. 2, among which 82 and 87 genes were found in the At- and Dt- subgenome, respectively. The number of PUB genes on chromosome D07 was the most and chromosome D08 was the least compared with 

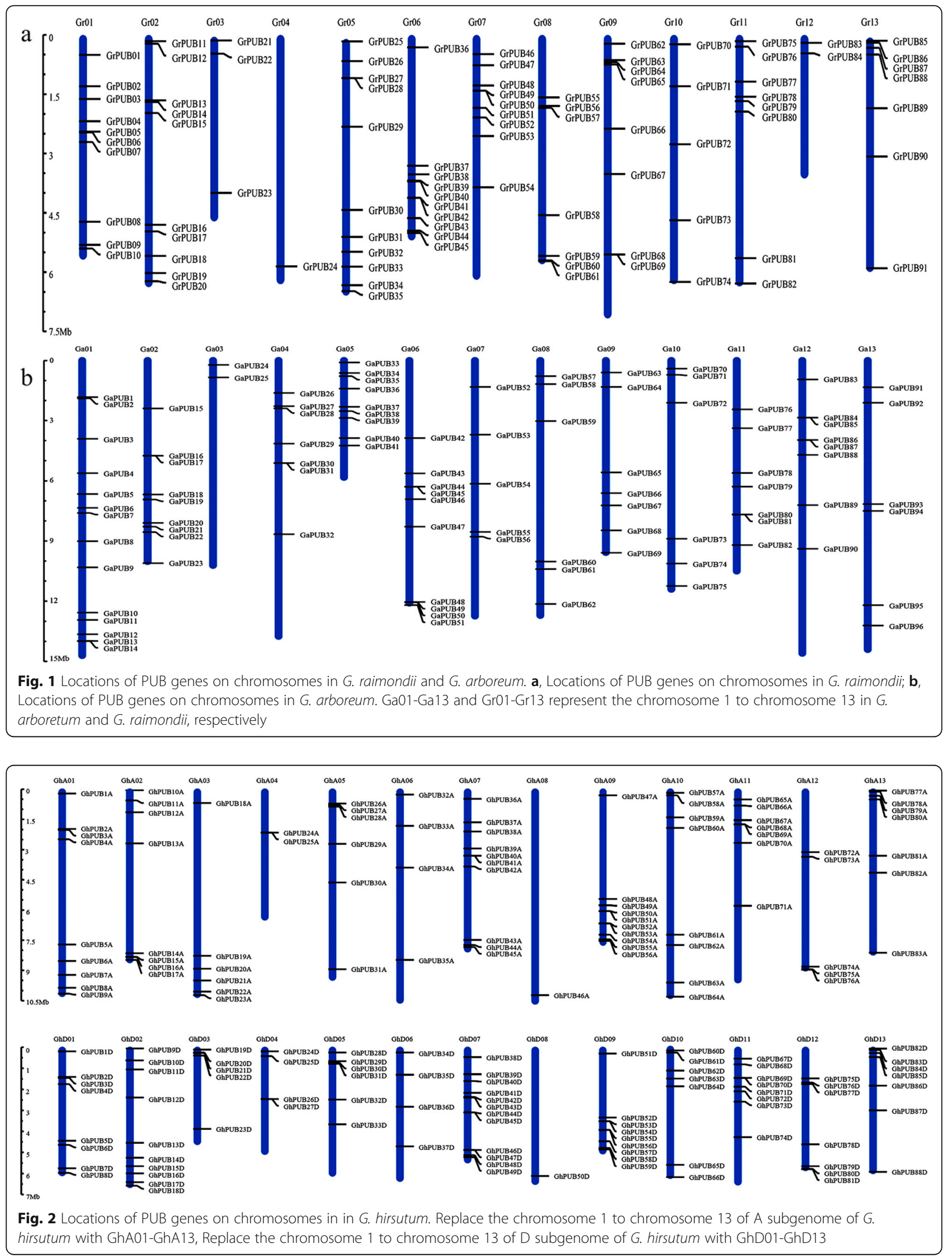
other chromosomes in both At- and Dt- subgenomes of G. hirsutum, showing that PUBs on these two chromosomes were relatively conserved and significant for cotton growth. The situation for G. barbadense was different with that of $G$. hirsutum (Additional file 11: Fig. S6). These results indicated that the PUB genes were equally distributed in At- and Dt- subgenomes but unevenly localized on each chromosome, which may be correlated with the differentiation of these species.

\section{Gene duplication analysis}

Fragment duplications in the genome region may result in the scattering of the gene family members. Compared with other eukaryotes, plants always have a higher rate of gene replication. Recent studies have shown that G. raimondii have had at least two complete genome-wide replicates [26]. The segregation of diploid cotton A genome and $\mathrm{D}$ genome occurred about 5-10 Myr years ago [18], and allotetraploid G. hirsutum was generated from the hybridization of diploid cottons and the number of chromosomes were doubled 1-2 Myr years ago. In the study, BLAST2.2.31+ (ftp://ftp.ncbi. nlm.nih.gov/blast/executables /blast+/LATEST/) was used for BLASTN and BLASTP (value 10) screening of homologous gene pairs from the cotton PUB genes identified. The uneven distribution of PUB genes on the chromosome may be correlated with the gene duplication or partial fragment replication events during the long evolutionary history of the cotton genome. Each time the replication event occurs, the entire genetic sequence of the cotton is doubled, and over time, these redundant genes are recombined or lost [23]. Previous studies have shown that gene duplication and postsegregation phenomena are two major driving forces of evolution [27]. Based on the multiple sequence alignment of the encoding sequences and the proteins in diploid cotton, 18 and 27 homologous gene-pairs were discovered with MCScanX [28] in G. raimondii (D5) (Additional file 12: Fig. S7A) and G. arboreum (A2) (Additional file 12: Fig. S7B), respectively. Among these homologous gene-pairs, 15 segmental duplications and 3 tandem duplications were found in $G$. raimondii, and 25 segmental duplications and 2 tandem duplications were found in G. arboreum. The relationship between these two diploid cottons and G. hirsutum was analyzed (Additional file 13: Fig. S8). Totally 197 homologous gene-pairs were found between G. raimondii and G. hirsutum, among which $58.89 \%$ (116/197) were located in the Dt-subgenome, and 191 homologous gene-pairs were found in both G. arboreum and G. hirsutum, among of which 55.50\%(106/191) were located in the At-subgenome. All these results indicated that more than half of homologous genes in G. hirsutum were derived from the corresponding diploid cotton genomes. Furthermore, approximately 41.11$44.50 \%$ of these homologous genes were originated from other diploid genomes.

\section{Expression pattern analysis of PUB genes in cotton}

Based on previous transcriptome data of the PUBs under different stresses (including salt, drought, hot and cold) in G. hirsutum, 117, 148 and 119 PUB genes were found with FPKM $>1$ in roots, stems and leaves, respectively, displaying tissue specificity. Among all the PUB genes, approximately 21 non-expressed PUB genes were identified in three tissues, and they may be associated with other specific regulation functions. All the PUB genes were categorized into five subgroups (I, II, III, IV and $\mathrm{V}$ ), and similar expression patterns were found among all PUB genes (Additional file 14: Fig. S9 and Additional file 15: Fig. S10). In subgroup I, 18 PUB genes with profound expression differences were discovered; in addition, other PUB genes in subgroup II- IV were found to have a consistent expression pattern under different stresses. However, 4 PUB genes (GhPUB32A GhPUB38D) in subgroup V showed a small expression difference under different stresses.

The evolution relationship in Additional 10: Fig. S5 showed GhPUB68A, GhPUB85A, GhPUB45D and GhPUB69D were belonged to subgroup III, indicating that their close relationship with each other. The transcriptome data showed that GhPUB85A and GhPUB45D were highly expressed whereas GhPUB68A and GhPUB69D were negligibly expressed. To investigate the functions of the homologous genes in cotton, qRT-PCR was used to investigate the expression difference in G. hirsutum TM-1. Drought, salt and cold treatments were applied and the results were present in Fig. 3. High expression of GhPUB85A and GhPUB45D under three stresses suggested that they were actively respond to the abiotic stresses, but GhPUB68A and GhPUB69D were not, which was in line with previously reported transcriptome data. Interestingly, we found that GhPUB85A and GhPUB45D were highly expressed at $6 \mathrm{~h}$ under drought stress, while the expressions at $12 \mathrm{~h}$ were the highest under salt and cold stress, indicating that GhPUB85A and GhPUB45D responded to drought stress faster than they did to salt and cold stresses. However, the expression values of GhPUB85A and GhPUB45D were significantly different under the same stress conditions, showing their different contributions in responding to abiotic stresses.

In addition, GhPUB85A and GhPUB45D were cloned using cDNA from G. hirsutum TM-1, and ligated to pEASY-Blunt Cloning Vector for sequencing to verify whether the vector was correctly ligated. The sequencing and enzyme digestion results showed that the recombined vectors were correctly constructed. Red fluorescence vectors pBI121-GhPUB85A:RFP and pBI121GhPUB45D:RFP were constructed to research their subcellular localizations, and the results showed that these two genes were located at the cytomembrane, as shown in Fig. 4, which were consistent with our prediction in Additional file 2: Table S2. In addition, two VIGS 

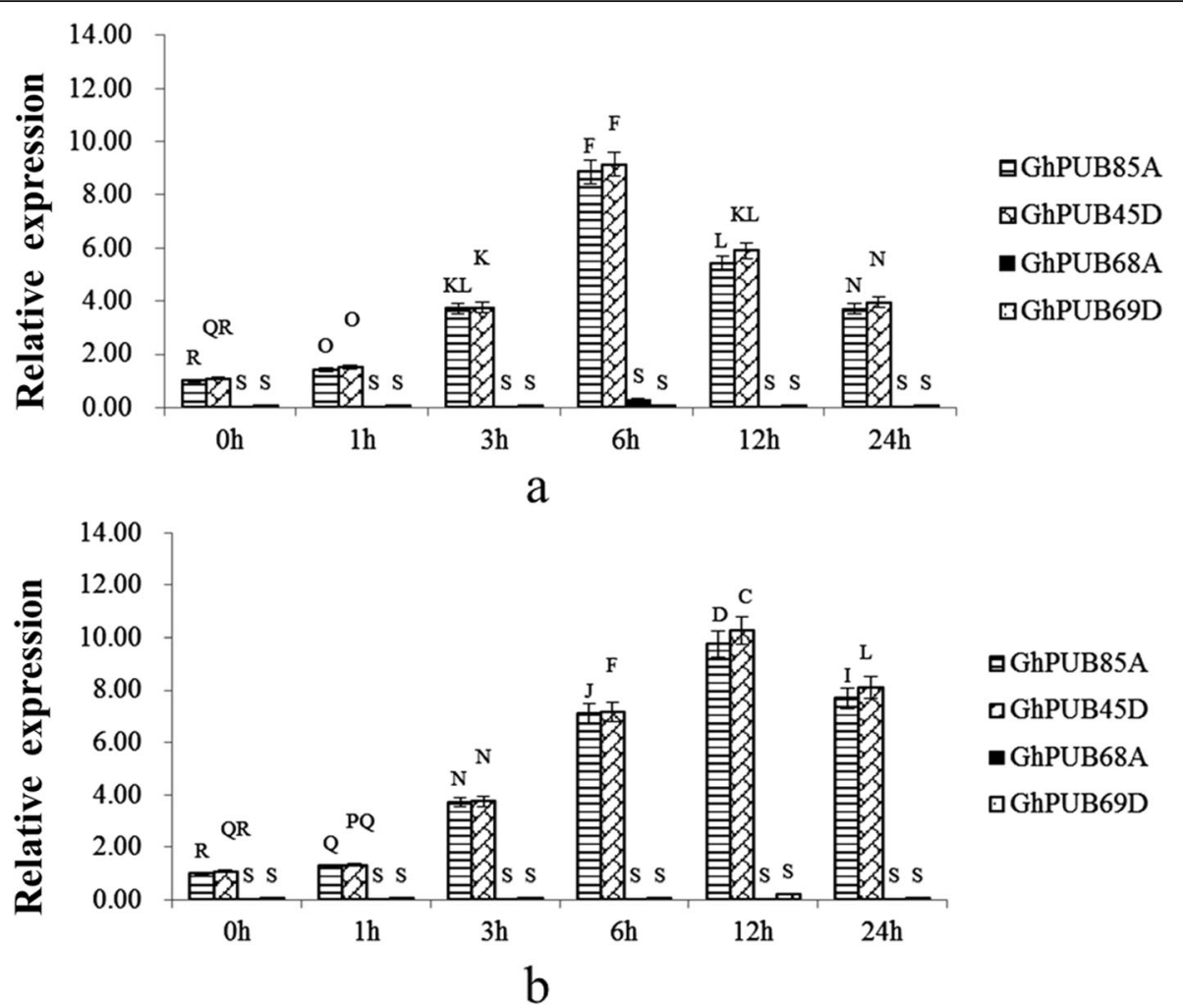

घGhPUB85A

口GhPUB45D

-GhPUB68A

๑GhPUB69D

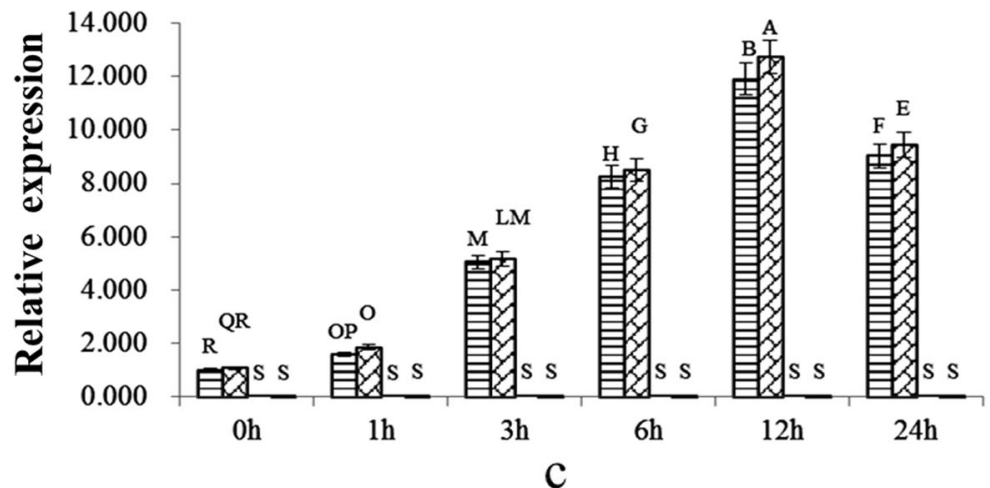

日GhPUB85A

口GhPUB45D

-GhPUB68A

口GhPUB69D

Fig. 3 Expression patterns of GhPUB68A、GhPUB85A、GhPUB45D and GhPUB69D during the drought, salt or low temperature stress. a, b and $\mathbf{c}$ represent drought, salt and low-temperature treatment, respectively. Different letters from A to $S$ indicate significance expression of different genes during different stresses $(p<0.01)$

vectors pYL156:GhPUB85A and pYL156:GhPUB45D were constructed using In-Fusion technology to study their functions under different stresses. Fifteen days after the VIGS infection, albino leaves of the positive control plants were observed, and all newly-emerged leaves were white in the later stage, while the others were normal with no albino leaves (Fig. 5a). We investigated the expression quantity in the control plants (CK), and pYL156-, pYL156:GhPUB85A- and pYL156:GhPUB45Dinfected plants under different stresses. The expression levels of two genes decreased significantly after the VIGS infection under different treatments showed their positive functions in responding to multiple stresses and the success of VIGS infection (Fig. 5b-d), indicating the VIGS infection technology was an effective way to study the gene functions in cotton.

\section{Discussion}

The PUB gene family has been identified and analyzed in a number of plants $[10,12-14]$. In this study, bioinformatics analysis was performed on allotetraploid cotton genomes $\mathrm{AD}_{1}$ and $\mathrm{AD} 2$, and diploid cotton genomes $A_{2}$ and $D_{5}$, and finally a total of 582 PUB genes were identified, including 185 genes in $\mathrm{AD}_{1}$ genome, 208 in $\mathrm{AD} 2$ genome, 96 in $\mathrm{A}_{2}$ genome, and 93 in $\mathrm{D}_{5}$ genome, indicating that it was a relatively conserved family in 


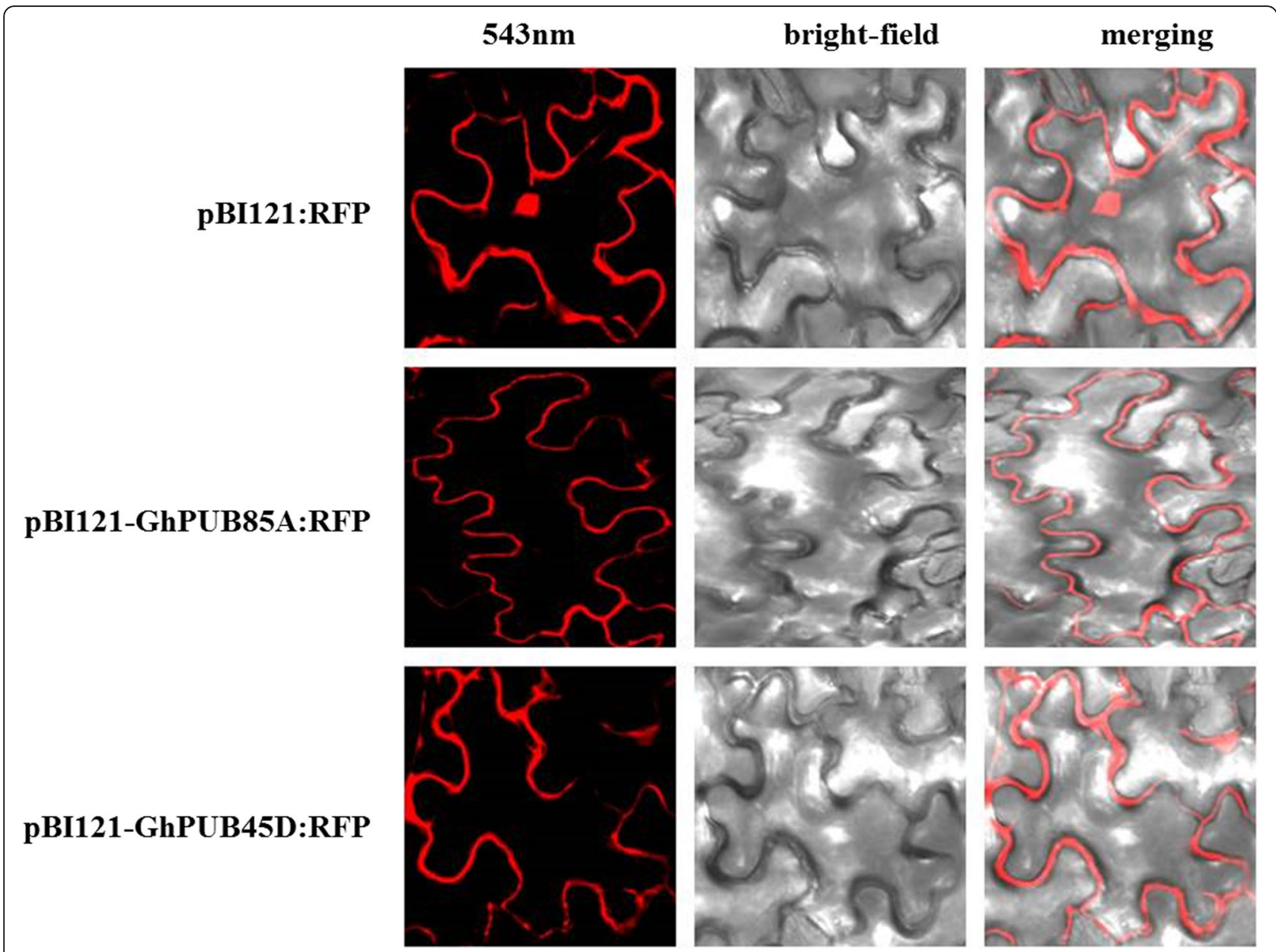

Fig. 4 Subcellular localization of GhPUB85A and GhPUB45D

terms of cotton genome evolution. Whole-genome replication analysis revealed that the ancestors of G. arboreum. and G. raimondii had undergone a cotton-specific genome-wide replication event that occurred about 1.6 million years ago after the differentiation from cocoa about 33 million years ago [29]. Recent studies have shown that $G$. raimondii has undergone at least two complete genome-wide replications [24, 30], resulting in an uneven distribution of the PUB genes on the chromosomes, and over the time of the cotton evolution, some genes are reassembled or lost. The results also showed that 19 of the 96 PUB genes in G. arboreum were generated through tandem repeats, which was one of the main reasons for the expansion of this gene family. Gene duplication event is a common phenomenon in plants, including multiple forms, such as tandem duplication, segmental duplication, and whole-genome duplication $[31,32]$. Some of duplicated genes could be retained in its descendants, which could provide original genetic resource for adaptive evolution of plants [33]. In this research, gene duplication event was commonly found, totally 31 and 27 gene pairs were discovered in D5 and A2 genome, respectively. In G. hirsutum, more gene pairs were found than the sum of A2 and D5, which might be associated with the higher resistance and wider adaptability of G. hirsutum.

The classification of PUB protein differs from that of the other gene families - it depends not only on U-box homology but also on domains other than U-box domains [34]. The evolutionary relationship of PUB genes between different cotton species is close, and the genetic structure in cotton is highly conserved. During the process of cotton evolution, in addition to the U-box domain, some other domains retained the basic functions of the family and enriched the diversity of PUB genes. Gene structure analysis showed that exon number of PUB genes varied greatly from 1 to 25 , which might be due to the directional evolution in the function and structure of PUB genes during the long evolutionary history. All PUB genes could be divided into five subgroups (I-V) in each species according to the evolutionary relationship, which was different with the classification of 


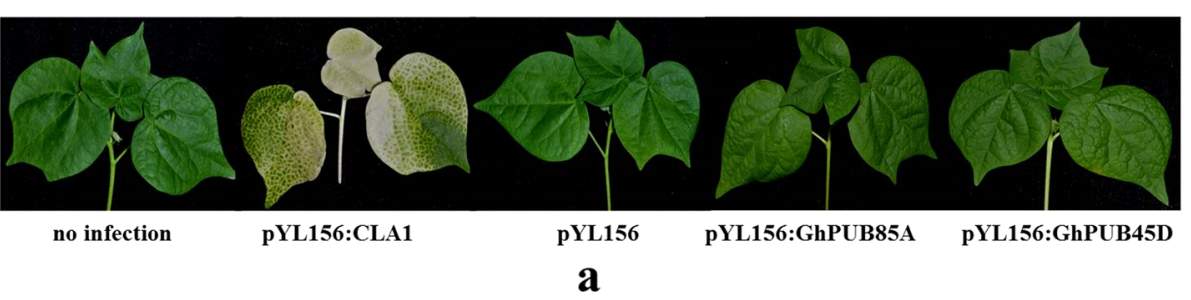

GhPUB85A

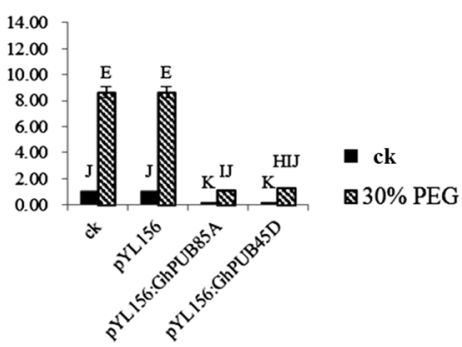

GhPUB85A

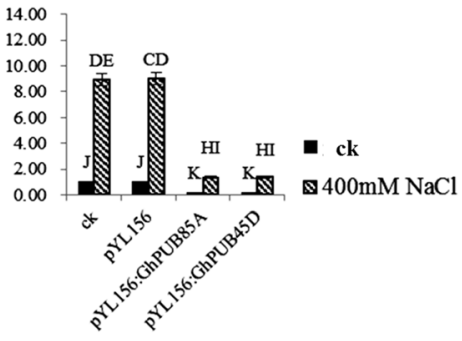

GhPUB85A

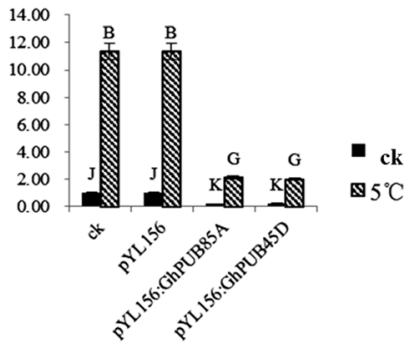

GhPUB45D

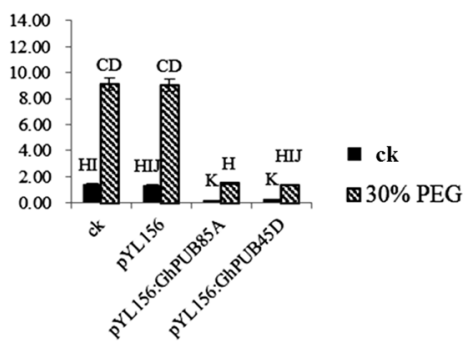

GhPUB45D

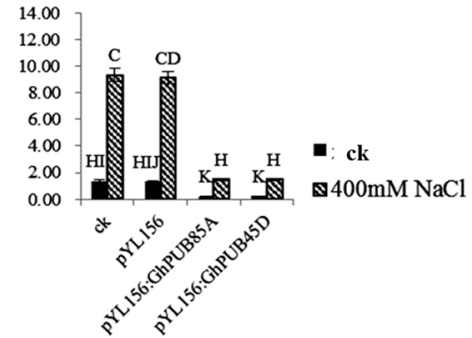

GhPUB45D

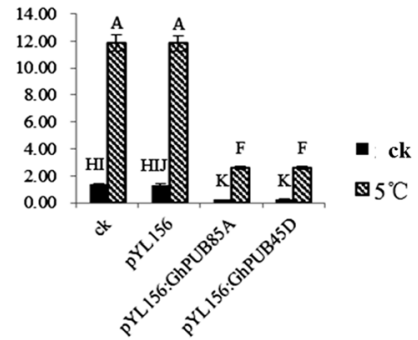

Fig. 5 The phenotype of cotton leaves after virus infection and expression analysis of GhPUB45D and GhPUB69D under the drought, salt and low temperature stress. $\mathbf{a}, \mathbf{b}$ and $\mathbf{c}$ represent drought ( $30 \% \mathrm{PEG})$, salt $(400 \mathrm{mM} \mathrm{NaCl})$ and low-temperature treatment $\left(5{ }^{\circ} \mathrm{C}\right)$, respectively. Different letters from $\mathrm{A}$ to $\mathrm{K}$ indicate significance expression of different genes during different stresses $(p<0.01)$

U-box containing genes in C.reinhardtii [11]. In the study, subgroup II and IV were found containing only 4 and 2 PUB genes, respectively. These findings suggested that the gene structures and evolutionary relationship of PUB family members were significantly different between different species. Previous studies have demonstrated that plant U-box containing genes are widely involved in stress responses, disease resistance and nutrient defect responses in plants [35-37]. In this study, $89 \%$ of PUB genes were differentially expressed in three tissues under salt, drought, cold and hot stresses, which also proved that PUB genes played important roles in abiotic responses. Twenty two PUB genes, including 18 genes from GhPUB8A to GhPUB51D in subgroup I and 4 genes from GhPUB32A to GhPUB38D in subgroup V, showed significant expression differences under different abiotic stresses, suggesting that they evolved toward specific functions in the long history. This perspective was consistent with previous documents [38, 39].

Many studies have shown that PUB genes play an important role in the process of stress responses in plants. For example, the overexpression of AtCHIP gene in Arabidopsis resulted in its sensitivity to high temperature and low temperature [40], while the AtPUB18, AtPUB19, 
AtPUB22 and AtPUB23 responded positively to drought $[16,30,35]$. In this study, two homologous PUB genes GhPUB85A and GhPUB45D were discovered with the same length of ORFs, type of protein, and subcellular localizations. The only difference was their locations on chromosomes, GhPUB85A on chromosome A07 in Atsubgenome while GhPUB45D on chromosome D07 in Dt-subgenome, which was not reported before. In addition, these two PUB genes GhPUB85A and GhPUB $45 D$ were cloned and functionally evaluated. Significant expression difference revealed that the functions of these homologous genes were similar in response to abiotic stresses, but their contributions differed from each other. Both of GhPUB85A and GhPUB45D contained the protein domain TPR, which was the same with $A t C H I P$, so we speculated that the functions of these two genes might be similar with AtCHIP [40], at least in response to cold stress which had been verified in the study. The results in this study laid a foundation for the further study of PUB genes of in cotton in future.

\section{Conclusions}

Genome-wide identification and expression analysis of PUB family members in cotton in this manuscript provided insights into response mechanism to abiotic stresses. Although the PUBs were highly conserved throughout the evolutionary history of cotton, significant differences were found between each other in gene structure. In addition, two homologous genes GhPUB85A and GhPUB45D were cloned and functionally identified. Expression pattern analysis showed they both responded to abiotic stresses positively, but their contributions were different. Therefore all these results were of great significance for the future research of molecular mechanism in responding to abiotic stresses.

\section{Methods}

Planting of cotton and Nicotiana benthamiana seedlings Upland cotton variety ZhongS9612, preserved by the Cotton Adversity Research Laboratory at the Chinese Academy of Agricultural Sciences (CAAS) for many years, was selected and used in the research. Before planting into sand, the seeds were surface-sterilized with $0.1 \% \mathrm{HgCl}_{2}$ and placed in a sterile dish with moist filter paper to accelerate germination. Uniform seedlings were chosen and transplanted into sand pots (10 plants in each pot) in a greenhouse $\left(14 \mathrm{~h} /\right.$ day at $30^{\circ} \mathrm{C}$ and 10 $\mathrm{h} /$ night at $24^{\circ} \mathrm{C}$ ) at the Institute of Cotton Research of CAAS. The cotton seedlings were treated with $200 \mathrm{ml}$ 30\% PEG 6000 and $200 \mathrm{ml} 400 \mathrm{mM} \mathrm{NaCl}$ solution, which could achieve completely consistent stress environments for each seedling in one pot. For the cold treatment, cotton seedlings were transferred into a $5{ }^{\circ} \mathrm{C}$ refrigerator with clear glass, but the light condition was not changed. For the planting of Nicotiana benthamiana, we first placed the seeds on MS medium at $22{ }^{\circ} \mathrm{C}$ in a growth chamber with a 16-h light cycle for the germination. After the emergence, the tobacco seedlings were moved to nutritionenriched soil for growth under the same condition for about 45 days. After the treatment, plant leaves were harvested and frozen with liquid nitrogen for use. For the agrobacteriummediated transformation, we referred the method used by Lu et al. [41].

\section{Whole genome identification of PUBs in cotton}

Cotton genome data (G. raimondii (D5) [20, 21], G. arboretum (A2) [22], and G. hirsutum acc. TM-1 (AD1) [23, 24] were obtained from CottonGene (https://www. cottongen.org/). The hidden Markov Model (HMM) profile of the U-box domain (PF04564) was obtained from Pfam30.0 (http://pfam.xfam.org/) [42], and was used as a query to identify the candidate PUBs from the cotton genome protein database using HMMER3.0 [43]. We used BLAST2.2.31+ (ftp://ftp.ncbi.nlm.nih.gov/blast/ executables/blast+/LATEST/) to obtain the coding domain sequences (CDSs) sequences, protein sequences and the corresponding full-length sequence in the genome. The protein sequences were further analyzed in the SMART (http://smart.embl-heidelberg.de/) and Pfam 30.0 [42] databases to ensure that each candidate protein contained a U-box domain. A subcellular localization prediction was carried out in CELLO v.2.5 [44].

\section{Analysis of gene structure, phylogenetic relationship and conserved domain}

All CDS sequences identified and the genome sequence of the PUBs were used to analyze the gene structure with software GSDS2.0 [26]. The full-length sequences of PUB proteins were used to construct a phylogenetic tree. Multi-sequence alignment of the PUBs was carried out by ClustalX1.83, and Neighbor-Joining (NJ) method [45] was used to construct a phylogenetic tree in MEGA6.0 [27]. The online software SMART, PROSITE [29] was used to analyze the conserved domains of each protein.

\section{Physical location of PUBs on the chromosome}

GFF (general feature format) information of the cotton PUBs were obtained from the genome annotation files. The distribution of cotton PUBs on the chromosome was generated with MapInspect (http://mapinspect.software. informer. com/).

\section{Gene duplication and micro-synteny analysis in $G$. arboreum, G. raimondii and G. hirsutum L}

Homologous gene pairs were identified according to multiple sequence alignment results and the standard was described in previous studies $[46,47]$. The collinearity of homologous genes was visualized with program Circos-0.69 [48] based on the homology between each species and their positions on the genome. 


\section{Gene cloning and the construction of vectors}

The first strand was synthesized according to the instructions of the TransScript One-step gDNA Removal and cDNA Synthesis Supermix kit. Two homologous genes GhPUB85A and GhPUB45D were cloned using In-fusion technology. Primers were designed using the online software and sequence information was present in Additional file 1: Table S1. The PCR amplification products were verified using $1.5 \%$ agarose gel electrophoresis. PCR amplification products were purified using the MiniBEST Agarose Gel DNA Extraction Kit from Takara Corporation. Finally the concentration of targets was measured, and stored at $-20^{\circ} \mathrm{C}$ for use.

Purified targets were linked to the pEASY-Blunt Cloning Vector, and then transformed into E. coli according to the instructions of pEASY-Blunt Cloning Kit. The transformation was conducted with heat-shock method, which was a classically effective approach. First a mixture of vectors and products was prepared with a mole ratio of $1: 7$ before the reaction in $200 \mu \mathrm{l}$ centrifuge tube at $25^{\circ} \mathrm{C}$ for $5 \mathrm{~min}$. Second blend the linked products and E. coli $\mathrm{DH} 5 \alpha$ cells when $E$. coli DH $5 \alpha$ cells began to dissolve, then the reaction was performed on the ice for $30 \mathrm{~min}$. Thirdly transfer the centrifuge tubes to $42^{\circ} \mathrm{C}$ water for $90 \mathrm{~s}$ to end the reaction, at last placed the centrifuge tubes on the ice for use. Positive clones were selected and inoculated into LB liquid medium containing Kana $\left(50 \mathrm{mg} \cdot \mathrm{L}^{-1}\right)$ for about $6 \mathrm{~h}$ under the conditions of $200 \mathrm{rpm}$ and $37^{\circ} \mathrm{C}$. Then the positive clones were verified using PCR amplification with primers. Finally cloning vectors GhPUB85A-t and GhPUB45D-t were obtained. PCR reaction system used in the research was below: $5 \times$ PrimerSTAR GXL Buffer, $10.0 \mu \mathrm{l}$; dNTP Mixture (2.5 mM each), $4.0 \mu \mathrm{l}$; Fprimer $(10 \mu \mathrm{M}), 1.5 \mu \mathrm{l}$; R-primer $(10 \mu \mathrm{M}), 1.5 \mu \mathrm{l}$; CDNA, 100 ng; $5 \times$ PrimerSTAR GXL DNA Polymerase, $100 \mathrm{ng}, 5 \times$ PrimerSTAR GXL DNA Polymerase, $2.0 \mu \mathrm{l}$; add $\mathrm{ddH}_{2} \mathrm{O}$ to $50.0 \mu$ l. PCR procedure of gene amplification used in the research was: $98^{\circ} \mathrm{C}, 10 \mathrm{~s} ; 55^{\circ} \mathrm{C}, 15 \mathrm{~s} ; 68^{\circ} \mathrm{C}, 9 \mathrm{~s} ; 4^{\circ} \mathrm{C}$, forever, 35 cycles. Real-time PCR method was used to measure the relative expression of two genes. Primers of two genes were listed in Additional file 1: Table S1. GhHistone3 gene (AF02471) was used as the reference gene.

\section{VIGS analysis of GhPUB85A and GhPUB45D}

Based on the vector sequence, target gene sequence and enzyme cutting sites, In-fusion primers were designed at the website (http://bioinfo.clontech.com/infusion). Primer sequences of InGhPUB85A-V, InGhPUB45D-V, GhPUBsRFP and InGhPUBs were listed in Additional file 1: Table S1. Finally the silencing vectors pYL156:GhPUB85A and pYL156:GhPUB45D, and RFP vectors pBI121GhPUB85A:RFP and pBI121-GhPUB45D:RFP, and the Plant overexpression vectors pBI121:GhPUB85A and pBI121:GhPUB45D were all successfully constructed. Vectors were transformed into cotton and tobacco with agrobacterium mediated genetic transformation method.

\section{Supplementary information}

Supplementary information accompanies this paper at https://doi.org/10. 1186/s12864-020-6638-5.

Additional file $\mathbf{1}$ Table S1. Primers used in the manuscript.

Additional file $\mathbf{2}$ Table S2. Essential information of PUB gene members in Gossypium raimondii.

Additional file $\mathbf{3}$ Table S3. Essential information of PUB gene members in Gossypium arboreum.

Additional file $\mathbf{4}$ Table S4. Essential information of PUB gene members in Gossypium hirsutum L.

Additional file $\mathbf{5}$ Table S5. Essential information of PUB gene members in Gossypium barbadense.

Additional file 6 Fig. S1. The phylogenetic relationship and gene structure analysis of GrPUBs in G. raimondii.

Additional file $\mathbf{7}$ Fig. S2. The phylogenetic relationship and gene structure analysis of GaPUBs in G. arboreum.

Additional file $\mathbf{8}$ Fig. S3. The phylogenetic relationship and gene structure analysis of GhPUBs in G. hirsutum.

Additional file 9 Fig. S4. The phylogenetic relationship and gene structure analysis of GbPUBs in G. barbadense.

Additional file 10 Fig. S5. The phylogenetic relationship analysis of PUBs in Gossypium.

Additional file 11 Fig. S6. Distrbution of GbPUBs on chromosomes in G. barbadense.

Additional file 12 Fig. S7. The homologous relationships of PUBs in G. raimondii and $G$. arboreum.

Additional file $\mathbf{1 3}$ Fig. S8. The intra- and inter-genomic synteny blocks of PUBs.

Additional file 14 Fig. S9. Predicted expression pattern of GhPUBs in upland cotton under salt and drought stress.

Additional file 15 Fig. S10. Predicted expression pattern of GhPUBs in upland cotton under cold and heat stress.

\section{Abbreviations}

APC: Anaphase-promoting complex; NJ: Neighbor-Joining; PUB: U-box gene; SCF: Skp1-cullin-F-box; VBC: VHL-Elongin B-Elongin C

\section{Acknowledgements}

We thank all members of our laboratories for the helpful assistances during the research. We also were grateful for the assistance of manuscript revisions by John Z. Yu from Crop Germplasm Research Unit, Southern Plains Agricultural Research Center, US Department of Agriculture, College Station, TX, USA.

\section{Authors' contributions}

$\mathrm{XL}$ participated in study design, data analysis, and manuscript writing; NS, $X C, B Z, S W, D W, J W$ and LG collected and analyzed data. WY was responsible for the study design and manuscript revisions. CC made contributions to the language polishing and modifications in the manuscript. All authors have read and approved the final version of the manuscript.

\section{Funding}

This work was supported by grants from National Key Research and Development Program (2016YFD0101006).

\section{Availability of data and materials}

All data generated and results analyzed during this study are included in this article and its supplementary information. Transcriptome data used for the PUB gene expression analysis in Additional file 14 Fig. 59 and Additional file 15 Fig. S10 could be downloaded with the accession number PRJNA248163.

Ethics approval and consent to participate

All the cotton materials were collected from the Institute of Cotton Research, Chinese Academy of Agricultural Sciences, which are publicly and available for non- commercial purpose. 


\section{Consent for publication}

Not applicable.

\section{Competing interests}

The authors declare that they have no competing interests.

\section{Author details}

${ }^{1}$ State Key Laboratory of Cotton Biology/ Institute of Cotton Research, Chinese Academy of Agricultural Sciences / Key Laboratory for Cotton Genetic Improvement, Anyang 455000, Henan, China. ${ }^{2}$ Hanzhong Agricultural Science Institute, Hanzhong 723000, Shanxi, China.

Received: 13 June 2019 Accepted: 28 February 2020

Published online: 06 March 2020

\section{References}

1. Schulman BA, Harper JW. Ubiquitin-like protein activation by E1 enzymes: the apex for downstream signalling pathways. Nat Rev Mol Cell Bio. 2009; 10(5):319-31.

2. Ye YH, Rape M. Building ubiquitin chains: E2 enzymes at work. Nat Rev Mol Cell Bio. 2009;10(11):755-64.

3. Smalle J, Vierstra RD. The ubiquitin 265 proteasome proteolytic pathway. Annu Rev Plant Biol. 2004;55:555-90.

4. Moon J, Parry G, Estelle M. The ubiquitin-proteasome pathway and plant development. Plant Cell. 2004;16(12):3181-95.

5. Cyr DM, Hohfeld J, Patterson C. Protein quality control: U-box-containing E3 ubiquitin ligases join the fold. Trends Biochem Sci. 2002;27(7):368-75.

6. Harper JW, Burton JL, Solomon MJ. The anaphase-promoting complex: it's not just for mitosis any more. Genes Dev. 2002;16(17):2179-206.

7. Vierstra RD. The ubiquitin-26S proteasome system at the nexus of plant biology. Nat Rev Mol Cell Bio. 2009;10(6):385-97.

8. Jackson PK, Eldridge AG, Freed E, Furstenthal L, Hsu JY, Kaiser BK, Reimann JD. The lore of the RINGs: substrate recognition and catalysis by ubiquitin ligases. Trends Cell Biol. 2000;10(10):429-39.

9. Wiborg J, O'Shea C, Skriver K. Biochemical function of typical and variant Arabidopsis thaliana U-box E3 ubiquitin-protein ligases. Biochem J. 2008; 413(3):447-57.

10. Zeng LR, Park CH, Venu RC, Gough J, Wang GL. Classification, expression pattern, and E3 ligase activity assay of rice U-box-containing proteins. Mol Plant. 2008;1(5):800-15.

11. Luo Q, Li Y, Wang W, Fei X, Deng X. Genome-wide survey and expression analysis of Chlamydomonas reinhardtii U-box E3 ubiquitin ligases (CrPUBs) reveal a functional lipid metabolism module. PLoS One. 2015;10(3):e0122600.

12. Wang C, Duan W, Riquicho AR, Jing Z, Liu T, Hou X, Li Y. Genome-wide survey and expression analysis of the PUB family in Chinese cabbage (Brassica rapa ssp. pekinesis). Mol Gen Genomics. 2015;290(6):2241-60.

13. Wang N, Liu Y, Cong Y, Wang T, Zhong X, Yang S, Li Y, Gai J. Genome-wide identification of soybean U-box E3 ubiquitin ligases and roles of GmPUB8 in negative regulation of drought stress response in Arabidopsis. Plant Cell Physiol. 2016;57(6):1189-209.

14. Cho SK, Chung HS, Ryu MY, Park MJ, Lee MM, Bahk YY, Kim J, Pai HS, Kim WT. Heterologous expression and molecular and cellular characterization of CaPUB1 encoding a hot pepper U-box E3 ubiquitin ligase homolog. Plant Physiol. 2006;142(4):1664-82.

15. Cho SK, Ryu MY, Song C, Kwak JM, Kim WT. Arabidopsis PUB22 and PUB23 are homologous U-box E3 ubiquitin ligases that play combinatory roles in response to drought stress. Plant Cell. 2008;20(7):1899-914.

16. Liu YC, Wu YR, Huang XH, Sun J, Xie Q. AtPUB19, a U-box E3 ubiquitin ligase, negatively regulates Abscisic acid and drought responses in Arabidopsis thaliana. Mol Plant. 2011;4(6):938-46.

17. Park JJ, Yi J, Yoon J, Cho LH, Ping J, Jeong HJ, Cho SK, Kim WT, An G. OsPUB15, an E3 ubiquitin ligase, functions to reduce cellular oxidative stress during seedling establishment. Plant J. 2011;65(2):194-205.

18. Senchina DS, Alvarez I, Cronn RC, Liu B, Rong JK, Noyes RD, Paterson AH, Wing RA, Wilkins TA, Wendel JF. Rate variation among nuclear genes and the age of polyploidy in Gossypium. Mol Biol Evol. 2003;20(4):633-43.

19. Wendel JF, Cronn RC. Polyploidy and the evolutionary history of cotton. Adv Agron. 2003;78:139-86.

20. Paterson AH, Wendel JF, Gundlach H, Guo H, Jenkins J, Jin DC, Llewellyn D, Showmaker KC, Shu SQ, Udall J, et al. Repeated polyploidization of
Gossypium genomes and the evolution of spinnable cotton fibres. Nature. 2012:492(7429):423-7.

21. Wang KB, Wang ZW, Li FG, Ye WW, Wang JY, Song GL, Yue Z, Cong L, Shang HH, Zhu SL, et al. The draft genome of a diploid cotton Gossypium raimondii. Nat Genet. 2012;44(10):1098-103.

22. Li FG, Fan GY, Wang KB, Sun FM, Yuan YL, Song GL, Li Q, Ma ZY, Lu CR, Zou CS, et al. Genome sequence of the cultivated cotton Gossypium arboreum. Nat Genet. 2014;46(6):567-72.

23. Li F, Fan G, Lu C, Xiao G, Zou C, Kohel RJ, Ma Z, Shang H, Ma X, Wu J, et al. Genome sequence of cultivated upland cotton (Gossypium hirsutum TM-1) provides insights into genome evolution. Nat Biotechnol. 2015;33(5):524-30.

24. Zhang T, Hu Y, Jiang W, Fang L, Guan X, Chen J, Zhang J, Saski CA, Scheffler BE, Stelly DM, et al. Sequencing of allotetraploid cotton (Gossypium hirsutum L. acc. TM-1) provides a resource for fiber improvement. Nat Biotechnol. 2015;33(5):531-7.

25. Yuan D, Tang Z, Wang M, Gao W, Tu L, Jin X, Chen L, He Y, Zhang L, Zhu L, et al. The genome sequence of Sea-Island cotton (Gossypium barbadense) provides insights into the allopolyploidization and development of superior spinnable fibres. Sci Rep. 2015;5:17662.

26. Schauser L, Wieloch W, Stougaard J. Evolution of NIN-like proteins in Arabidopsis, rice, and Lotus japonicus. J Mol Evol. 2005;60(2):229-37.

27. Chothia C, Gough J, Vogel C, Teichmann SA. Evolution of the protein repertoire. Science. 2003;300(5626):1701-3.

28. Wang Y, Tang H, Debarry JD, Tan X, Li J, Wang X, Lee TH, Jin H, Marler B, Guo H, et al. MCScanX: a toolkit for detection and evolutionary analysis of gene synteny and collinearity. Nucleic Acids Res. 2012;40(7):e49.

29. Zhu YX, Li FG. The Gossypium raimondii genome, a huge leap forward in cotton genomics. J Integr Plant Biol. 2013;55(7):570-1.

30. Bergler J, Hoth S. Plant U-box armadillo repeat proteins AtPUB18 and AtPUB19 are involved in salt inhibition of germination in Arabidopsis. Plant Biol (Stuttg). 2011;13(5):725-30.

31. Kondrashov FA, Rogozin IB, Wolf YI, Koonin EV. Selection in the evolution of gene duplications. Genome biology. 2002;3(2):research0008.

32. Conant GC, Wolfe KH. Turning a hobby into a job: how duplicated genes find new functions. Nat Rev Genet. 2008;9(12):938-50.

33. Flagel LE, Wendel JF. Gene duplication and evolutionary novelty in plants. New Phytol. 2009;183(3):557-64.

34. Azevedo C, Santos-Rosa MJ, Shirasu K. The U-box protein family in plants. Trends Plant Sci. 2001;6(8):354-8.

35. Seo DH, Ryu MY, Jammes F, Hwang JH, Turek M, Kang BG, Kwak JM, Kim WT. Roles of four Arabidopsis U-box E3 ubiquitin ligases in negative regulation of abscisic acid-mediated drought stress responses. Plant Physiol. 2012;160(1):556-68.

36. Li W, Dai L, Wang GL. PUB13, a U-box/ARM E3 ligase, regulates plant defense, cell death, and flowering time. Plant Signal Behav. 2012;7(8):898-900.

37. Deb S, Sankaranarayanan S, Wewala G, Widdup E, Samuel MA. The S-domain receptor kinase Arabidopsis receptor Kinase2 and the $U$ box/Armadillo repeatcontaining E3 ubiquitin Ligase9 module mediates lateral root development under phosphate starvation in Arabidopsis. Plant Physiol. 2014;165(4):1647-56.

38. Wang L, Yang Z, Zhang B, Yu D, Liu J, Gong Q, Qanmber G, Li Y, Lu L, Lin Y, et al. Genome-wide characterization and phylogenetic analysis of GSK gene family in three species of cotton: evidence for a role of some GSKs in fiber development and responses to stress. BMC Plant Biol. 2018;18(1):330.

39. Mu M, Lu XK, Wang JJ, Wang DL, Yin ZJ, Wang S, Fan WL, Ye WW. Genome-wide identification and analysis of the stress-resistance function of the TPS (Trehalose6-phosphate synthase) gene family in cotton. BMC Genet. 2016;17:54.

40. Yan JQ, Wang J, Li QT, Hwang JR, Patterson C, Zhang H. AtCHIP, a U-boxcontaining E3 ubiquitin ligase, plays a critical role in temperature stress tolerance in Arabidopsis. Plant Physiol. 2003;132(2):861-9.

41. Lu X, Yin Z, Wang J, Chen X, Wang D, Wang S, Guo L, Fan W, Chen C, Wang $X$, et al. Identification and function analysis of drought-specific small RNAs in Gossypium hirsutum L. Plant Sci. 2019;280:187-96.

42. Finn RD, Coggill P, Eberhardt RY, Eddy SR, Mistry J, Mitchell AL, Potter SC, Punta M, Qureshi M, Sangrador-Vegas A, et al. The Pfam protein families database: towards a more sustainable future. Nucleic Acids Res. 2016:44(D1):D279-85.

43. Finn RD, Clements J, Arndt W, Miller BL, Wheeler TJ, Schreiber F, Bateman A, Eddy SR. HMMER web server: 2015 update. Nucleic Acids Res. 2015;43(W1):W30-8.

44. Yu CS, Chen YC, Lu CH, Hwang JK. Prediction of protein subcellular localization. Proteins. 2006:64(3):643-51.

45. Wei KF, Wang YM, Xie DX. Identification and expression profile analysis of the protein kinase gene superfamily in maize development. Mol Breeding. 2014;33(1):155-72 
46. Yang SH, Zhang XH, Yue JX, Tian DC, Chen JQ. Recent duplications dominate NBS-encoding gene expansion in two woody species. Mol Gen Genomics. 2008;280(3):187-98.

47. Gu ZL, Cavalcanti A, Chen FC, Bouman P, Li WH. Extent of gene duplication in the genomes of Drosophila, nematode, and yeast. Mol Biol Evol. 2002; 19(3):256-62.

48. Stone SL, Anderson EM, Mullen RT, Goring DR. ARC1 is an E3 ubiquitin ligase and promotes the ubiquitination of proteins during the rejection of self-incompatible Brassica pollen. Plant Cell. 2003;15(4):885-98.

\section{Publisher's Note}

Springer Nature remains neutral with regard to jurisdictional claims in published maps and institutional affiliations.

Ready to submit your research? Choose BMC and benefit from:

- fast, convenient online submission

- thorough peer review by experienced researchers in your field

- rapid publication on acceptance

- support for research data, including large and complex data types

- gold Open Access which fosters wider collaboration and increased citations

- maximum visibility for your research: over $100 \mathrm{M}$ website views per year

At $\mathrm{BMC}$, research is always in progress.

Learn more biomedcentral.com/submissions 